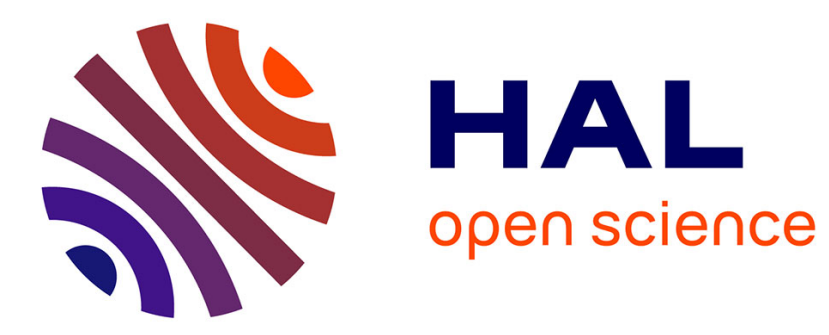

\title{
Passive coherent beam combining of two femtosecond fiber chirped-pulse amplifiers
}

Louis Daniault, Marc Hanna, Dimitris N. Papadopoulos, Yoann Zaouter, Eric Mottay, Frédéric Druon, Patrick Georges

\section{- To cite this version:}

Louis Daniault, Marc Hanna, Dimitris N. Papadopoulos, Yoann Zaouter, Eric Mottay, et al.. Passive coherent beam combining of two femtosecond fiber chirped-pulse amplifiers. Optics Letters, 2011, 36 (20), pp.4023-4025. hal-00702157

\section{HAL Id: hal-00702157 \\ https://hal-iogs.archives-ouvertes.fr/hal-00702157}

Submitted on 29 May 2012

HAL is a multi-disciplinary open access archive for the deposit and dissemination of scientific research documents, whether they are published or not. The documents may come from teaching and research institutions in France or abroad, or from public or private research centers.
L'archive ouverte pluridisciplinaire HAL, est destinée au dépôt et à la diffusion de documents scientifiques de niveau recherche, publiés ou non, émanant des établissements d'enseignement et de recherche français ou étrangers, des laboratoires publics ou privés. 


\title{
Passive coherent beam combining of two femtosecond fiber chirped-pulse amplifiers
}

\author{
Louis Daniault, ${ }^{1}$ Marc Hanna, ${ }^{1}$ Dimitris N. Papadopoulos, ${ }^{2}$ Yoann Zaouter, ${ }^{3}$ Eric Mottay, ${ }^{3}$ Frédéric \\ Druon, ${ }^{1}$ Patrick Georges ${ }^{1}$ \\ ${ }^{1}$ Laboratoire Charles Fabry, Institut d'Optique, Univ Paris-Sud, 91127 Palaiseau, France \\ ${ }^{2}$ Institut de la Lumière Extrême, CNRS, Ecole Polytechnique, ENSTA Paristech, Institut d'Optique, \\ Université Paris Sud, Palaiseau Cedex, France \\ ${ }^{3}$ Amplitude Systèmes, 11 avenue de Canteranne, Cité de la Photonics, 33600 Pessac, France \\ *Corresponding author: louis.daniault@institutoptique.fr
}

Received Month X, XXXX; revised Month X, XXXX; accepted Month X,

XXXX; posted Month X, XXXX (Doc. ID XXXXX); published Month X, XXXX

\begin{abstract}
We propose and demonstrate an architecture that achieves passive coherent combination of two fiber femtosecond chirpedpulse amplifiers. The setup consists in the use of a well-balanced amplifying Sagnac interferometer. The experiment shows that the temporal, spectral, and spatial qualities of each beam are retained, with the generation of $250 \mathrm{fs}$ pulses at $35 \mathrm{MHz}$ repetition rate, an uncompressed average power of $10 \mathrm{~W}$, and a combining efficiency of $96 \%$. The behavior of this architecture in the presence of high accumulated nonlinear phase is investigated. (C) 2010 Optical Society of America
\end{abstract} OCIS codes: $060.2320,140.3298,140.7090$

Ytterbium-doped fiber amplifiers have great advantages to amplify ultrashort femtosecond pulses. Indeed, their geometry offers a good thermal handling compared to bulk systems, allowing the generation of high average powers at high repetition rates. For most applications, fiber chirped-pulse amplifiers (FCPA) involve two stages. Starting from a high repetition rate oscillator that generates pulses in the $10 \mathrm{pJ}-1 \mathrm{~nJ}$ range, a pre-amplifier allows to obtain pulses at intermediate energies of $10 \mathrm{~nJ}$ $1 \mu \mathrm{J}$. A second power-amplifier is required to reach energies requested by most applications ranging from 10 $\mu \mathrm{J}$ to $1 \mathrm{~mJ}$ at average powers of tens to hundreds of Watt level.[1-2]. This last step is challenging because nonlinear effects appear at high peak-powers, especially self-phase modulation (SPM), which can strongly deteriorate the pulse properties. For the last years, a lot of efforts have been made on designing fiber power-amplifiers with larger core sizes, known as large mode area (LMA) fibers. These fibers exhibit lower nonlinearity, thereby increasing the maximum output peak-power achievable while maintaining good temporal pulse quality. Unfortunately, this cannot be considered as a fully scalable solution, as it is limited by the appearance of higher-order spatial modes.

Another way to scale the output power consists in coherently combine the output beams of several amplifiers that are seeded by the same source. This has been demonstrated in continuous wave [3] and recently experimented in nanosecond [4] and femtosecond regimes [5-6]. This approach is scalable by increasing the number of combined amplifiers, but requires an active control of the relative phase between them. This necessitates the implementation of a phase detection scheme, feedback electronics, and the insertion of a phase-controlling element in each amplifying arm. Passive coherent combination techniques have been investigated, but in this case the recombination is done within an oscillator [7], which limits their potential. Ultimately, a setup that performs passive coherent beam combining of amplifiers could be a real benefit for obtaining higher peak-powers with FCPA.

We demonstrate in this paper the passive coherent beam combining of two femtosecond FCPA. This system has the same complexity and efficiency as the standard two-stage scheme, but distributes the power over two channels, thereby reducing power-related issues. The relative phase between the two channels is self-matched, and no active control is required. This is achieved by using a Sagnac interferometer that allows two identical pulses to travel the exact same path in opposite directions. This setup has already been used for other purposes, such as nonlinear optical loop mirrors [8], where a dissymmetry between the two paths is exploited. In our case, the interferometer has to be as symmetrical as possible to efficiently combine the beams. We obtain output pulses of 250 fs with $10 \mathrm{~W}$ uncompressed average power at a repetition rate of $35 \mathrm{MHz}$ and a combining efficiency of $96 \%$. We also investigate this scheme in nonlinear regime, and show that the combining efficiency is well maintained in the presence of self-phase modulation (SPM).

The setup is described in Fig.1. The seed comes from an air-cooled $\mathrm{Yb}^{3+}: \mathrm{KYW}$ bulk oscillator that delivers $250 \mathrm{fs}$ pulses at $35 \mathrm{MHz}$ repetition rate. It is followed by a pulsepicker, and a stretcher that broadens the pulses to $150 \mathrm{ps}$. The beam is seeded into a Sagnac interferometer, whose output is directed to a compressor that exhibits an efficiency of $65 \%$. All output powers and energies in this paper are given before compression to illustrate the important parameter which is combining efficiency. The interferometer is made of an isolator and a polarizing 
beam splitter (PBS) that divides the seed into two crosspolarized waves with same power. Each of them are seeded into a $1.6 \mathrm{~m}$ length Yb-doped double-clad 30/150 $\mu \mathrm{m}$ polarization-maintaining LMA fiber amplifier. The respective outputs are collimated and reinjected into the other fiber, in opposite direction. Half wave-plates are used throughout the setup to match the polarization of the beams to the fibers principal axes. The optical isolator allows both coherent combination and extraction of the combined beam from the seed path. The first PBS projects the two polarizations at $45^{\circ}$ so that the beams can interfere, and its rejection corresponds to the uncombined part of the beam. The rotator and second PBS extract the combined beam out of the seed path. The combining efficiency is measured using these two outputs.

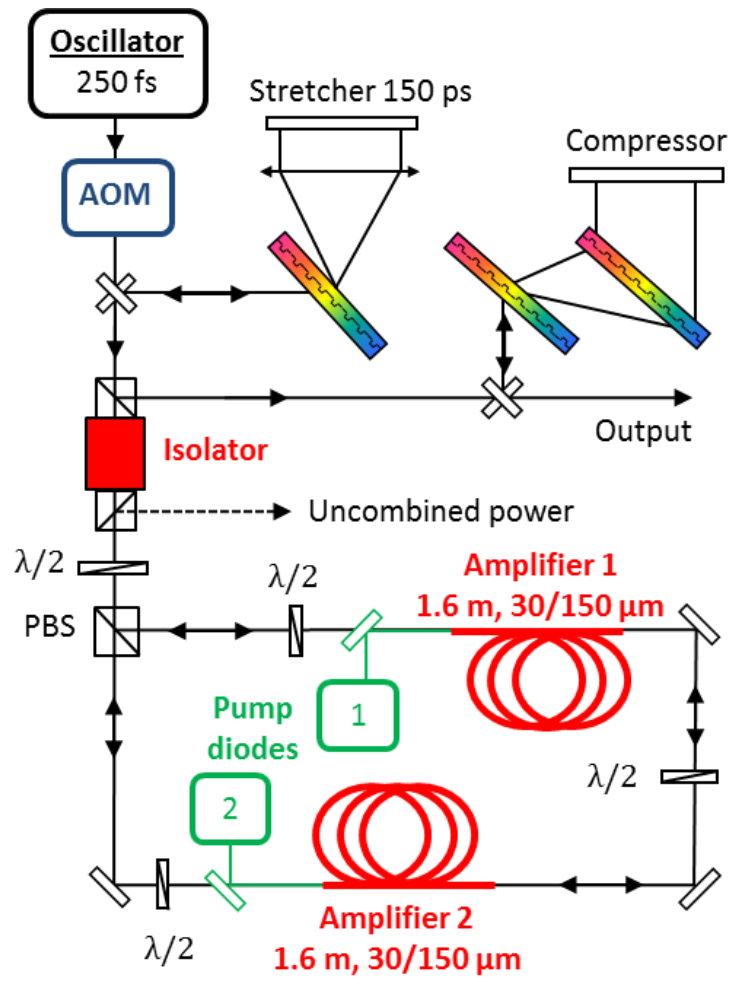

Fig. 1. (Color online) Experimental setup. AOM : acousto-optic modulator. PBS : Polarizing Beam Splitter.

At any time, each fiber amplifies two beams with different powers and propagation directions. They both work as pre-amplifier for one channel and as poweramplifier for the second one. The pumping is $\mathrm{co}^{-}$ propagative for the first pass, so that it is counterpropagative for the way back. This arrangement involves lower B-integrals due to SPM. The overall optical path length for one round-trip inside the Sagnac interferometer is $5 \mathrm{~m}$. This implies that the setup is not sensitive to phase noise frequency below $30 \mathrm{MHz}$, whereas thermal and acoustic noises do not extend significantly beyond 10 $\mathrm{kHz}$. The combination is thus very stable and robust to strong environmental perturbations. The setup has been operated first at $35 \mathrm{MHz}$ repetition rate, with a total seed power of $300 \mathrm{~mW}$. With $30 \mathrm{~W}$ total pump power, the output power is $10 \mathrm{~W}$ with a combining efficiency of $96 \%$. The non-perfect efficiency is essentially due to mismatch in the beam profiles and amplified spontaneous emission (ASE). The output pulsewidth is well retained, with an obtained duration of $250 \mathrm{fs}$ FWHM, as shown in Fig. 2.
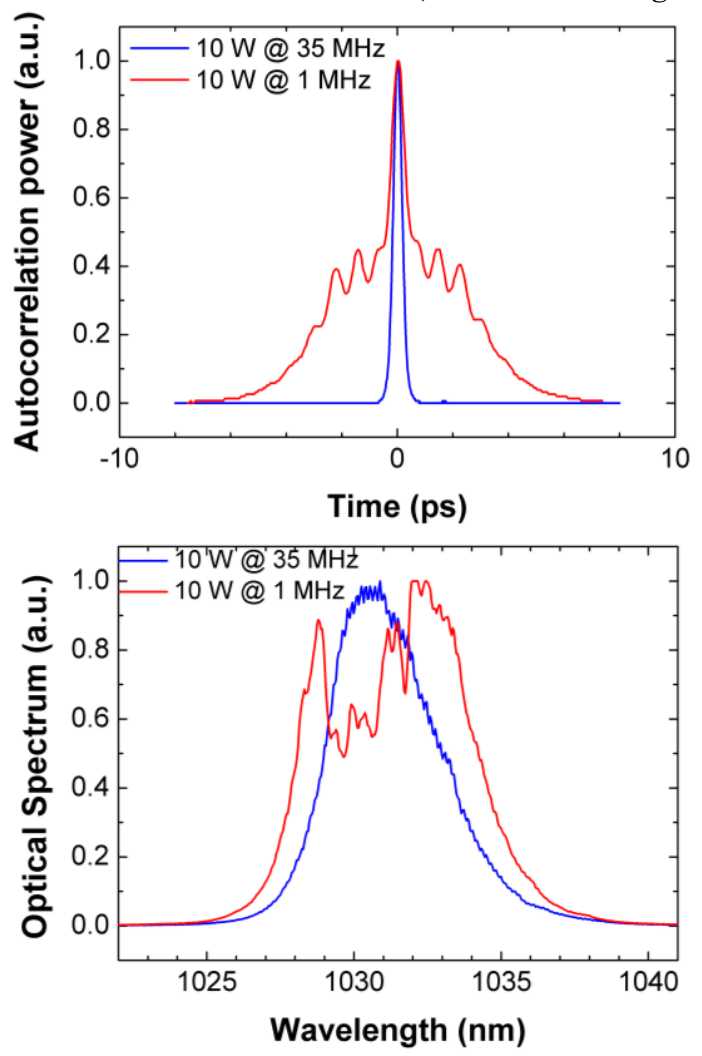

Fig. 2. (Color online) Autocorrelation power (top) and optical spectrum (bottom) of $10 \mathrm{~W}$ at $35 \mathrm{MHz}$ (blue) and $10 \mathrm{~W}$ at $1 \mathrm{MHz}$ (red) pulses.

To investigate the dependence of the combining efficiency to SPM, the repetition rate is set to $1 \mathrm{MHz}$. At this point, the accumulated nonlinear phase becomes nonnegligible and must be the same for the two counterpropagating beams to retain a good combining efficiency. This is done in practice by adjusting the pump powers and injection conditions, as demonstrated in [9]. Considering that SPM mainly occurs near the output of the poweramplifier, each pump power controls the nonlinear phase of one of the beams, with little effect on the other one. This is observed experimentally, and the tolerance on the pump power to remain at maximum efficiency is about $100 \mathrm{~mW}$. Figure 2 shows the spectrum and autocorrelation obtained at $10 \mathrm{~W}$ average power, corresponding to $10 \mu \mathrm{J}$ energy and estimated B-integral for each path of $12 \mathrm{rad}$. This high B-integral completely distorts the output pulse, but the corresponding combining efficiency is still $84 \%$.

This efficiency is plotted as a function of pulse energy in Fig. 3, at both $35 \mathrm{MHz}$ and $1 \mathrm{MHz}$ repetition rates. At identical output pulse energies, the difference in efficiency between the low and high repetition rate is due to the 
higher emitted ASE power at $1 \mathrm{MHz}$ repetition rate. We observe a slow decrease of the efficiency with pulse energy, even with a careful adjustment of the pump powers. This effect essentially comes from the mutual reinjections between the two fibers, which are not perfectly symmetrical. The nonlinear propagation is strongly affected by this parameter, and the relative spectral phase between both paths features higher-order terms that cannot be tuned independently. The power spectral densities of each path also present significant differences, as the temporal shapes do, which impacts more loosely on the combining efficiency. These limitations might be partially solved by replacing the two fibers by a single one with adequate length.

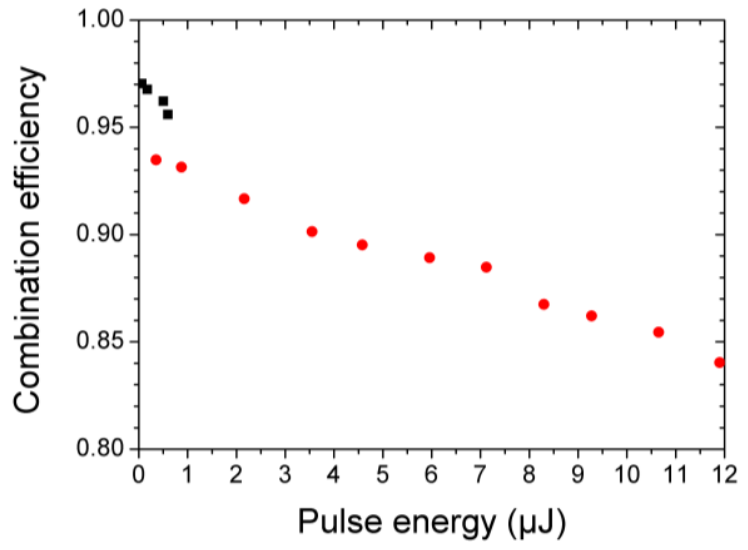

Fig. 3. (Color online) Combining efficiency as a function of pulse energy at $1 \mathrm{MHz}$ (red) and $35 \mathrm{MHz}$ (black) repetition rates.

To illustrate the advantage of this amplifying architecture, we compare it to a standard two-stage scheme by inserting an isolator inside the interferometer. In this last case, the compressor length has to be shortened to minimize the pulse duration, which is characteristic of stronger SPM effects. The autocorrelations obtained at $2 \mathrm{~W}$ output power and 1 $\mathrm{MHz}$ repetition rate are shown in Fig. 4 both for the combined geometry and for the standard two-stage setup.

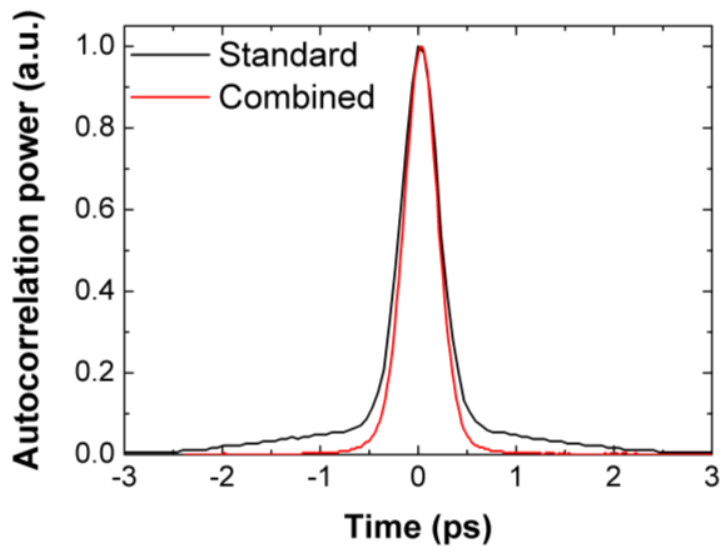

Fig. 4. (Color online) Autocorrelation for the standard two-stage architecture (black) and the combining architecture (blue).
The temporal distortions observed in the standard setup configuration do not appear in the combined case due to the lower B-integral, and the pulses remain Fouriertransform limited in the combined setup. Moreover, the measured power fluctuations of the combined beam are perfectly identical to the power fluctuations of each isolated channel, indicating that phase noise plays a negligible role in the output power stability.

The beam profile and the $\mathrm{M}^{2}$ are shown in Fig. 5. The obtained beam quality is good in all cases, following a careful adjustment of the relative tilt and defocus in both arms. This alignment is crucial to obtain high combining efficiency.

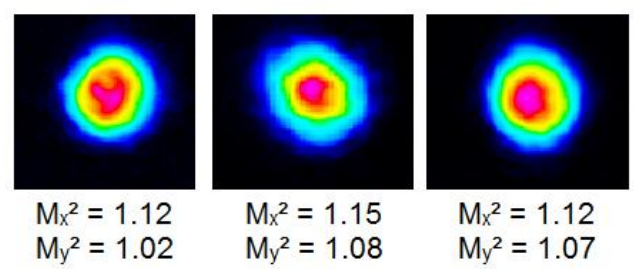

Fig. 5. (Color online) Beam profiles and $\mathrm{M}^{2}$ of one isolated channel (left), the second one (middle), and the combined beam (right).

In conclusion, we demonstrated passive coherent beam combining of two femtosecond FCPA, with $96 \%$ combining efficiency in the linear amplification regime, and a good tolerance to nonlinear effects. The setup is equivalent to a standard two-stage scheme in terms of complexity, output power and beam profiles, but distributes the peak and average power-related issues over two amplification paths. Although this architecture can only combine two beams, other schemes are being investigated to scale the number of passively combined amplifiers.

The research described here has been supported by Triangle de la Physique contract 2009-026T.

\section{References}

1. F. Röser, T. Eidam, J. Rothhardt, O. Schmidt, D. N. Schimpf, J. Limpert, and A. Tünnermann, Opt. Lett. 32, 3495-3497 (2007).

2. Y. Zaouter, J. Boullet, E. Mottay, and E. Cormier, Opt. Lett. 33, 1527 (2008).

3. T. Shay, V. Benham, J. T. Baker, A. D. Sanchez, D. Pilkington, and C. A. Lu, IEEE J. Sel. Top. Quantum Electron. 13, 480 (2007).

4. L. Lombard, A. Azarian, K. Cadoret, P. Bourdon, D. Goular, G. Canat, V. Jolivet, Y. Jaouën, and O. Vasseur, Opt. Lett. 36, 523-525 (2011).

5. L. Daniault, M. Hanna, L. Lombard, Y. Zaouter, E. Mottay, D. Goular, P. Bourdon, F. Druon, and P. Georges, Opt. Lett. 36, 621-623 (2011).

6. Enrico Seise, Arno Klenke, Sven Breitkopf, Marco Plötner, Jens Limpert, and Andreas Tünnermann, Opt. Lett. 36, 439-441 (2011).

7. Baishi Wang, Eric Mies, Monica Minden, and Anthony Sanchez, Opt. Lett. 34, 863-865 (2009).

8. N. J. Doran and David Wood, Opt. Lett. 13, 56-58 (1988).

9. S. Jiang, M. Hanna, F. Druon, and P. Georges, Opt. Lett. 35,1293 (2010). 